\title{
Implementation Status of Performance Demonstration Program for Steam Generator Tubing Analysts in Korea
}

\author{
Chan-Hee Cho*† ${ }^{\dagger}$, Hee-Jong Lee*, Hyun-Ju Yoo*, Min-Woo Nam* and Sung-Yull Hong**
}

\begin{abstract}
Some essential components in nuclear power plants are periodically inspected using non-destructive examinations, for example ultrasonic, eddy current and radiographic examinations, in order to determine their integrity. These components include nuclear power plant items such as vessels, containments, piping systems, pumps, valves, tubes and core support structure. Steam generator tubes have an important safety role because they constitute one of the primary barriers between the radioactive and non-radioactive sides of the nuclear power plant. There is potential that if a tube bursts while a plant is operating, radioactivity from the primary coolant system could escape directly to the atmosphere. Therefore, in-service inspections are critical in maintaining steam generator tube integrity. In general, the eddy current testing is widely used for the inspection of steam generator tubes due to its high inspection speed and flaw detectability on non-magnetic tubes. However, it is not easy to analyze correctly eddy current signals because they are influenced by many factors. Therefore, the performance of eddy current data analysts for steam generator tubing should be demonstrated comprehensively. In Korea, the performance of steam generator tubing analysts has been demonstrated using the Qualified Data Analyst program. This paper describes the performance demonstration program for steam generator tubing analysts and its implementation results in Korea. The pass rate of domestic analysts for this program was $71.4 \%$.
\end{abstract}

Keywords: Perfromance Demonstration, Eddy Current Testing, Nondestructive Examination, Steam Generator

\section{Introduction}

Nondestructive examination methods are used to detect surface and internal discontinuities in materials, welds, fabricated parts and components during the in-service inspection in nuclear power plants. They include ultrasonic, radiographic, eddy current examinations and so on. The eddy current testing is used for the inspection of steam generator tubes in nuclear power plants because it offers relatively low cost means for high speed, large scale testing of metallic materials under high pressure and temperature engineering systems. However, eddy current signals are influenced by not only flaw on the tube but also conductivity, permeability and geometry of the material. Each of eddy current signals encountered during the steam generator examination needs to be correctly evaluated and classified. A single missed or incorrectly classified defect indication can lead to a plant shutdown or a tube rupture event. To reduce the likelihood of these consequences, analysis for tube degradation data may be completed by two independent analysis teams which are designated as primary and secondary.

To maintain independence, the analyses should be done separately without knowledge of the other team's results. Two teams should be from different vendor organizations. A resolution team should review and resolve discrepancies between the results of the two independent analysis teams. In addition, eddy current analysts' performance should be demonstrated by a proper tool even if they are qualified by SNT-TC-1A [1] or ANSI/ASNT CP-189 [2].

[Received: April 14, 2012, Revised: June 7, 2012, Accepted: July 13, 2012] *KHNP-Central Research Institute, Daejeon 305-343, Korea, **School of Mechanical Engineering College of Engineering, Yeungnam University, Gyeongsan 712-749, Korea †Corresponding Author: chanhee@khnp.co.kr

(C) 2013, Korean Society for Nondestructive Testing 
In Korea, the Qualified Data Analyst (QDA) program has been used for the analyst's performance demonstration since 2004 in accordance with the Notice 2012-10 of the Nuclear Safety and Security Commission [3] and the steam generator examination guidelines of the Electric Power Research Institute (EPRI) [4]. The purpose of this performance demonstration program is to ensure a uniform knowledge and skill level of data analysts and contribute to safely operate the nuclear power plant. Written and practical examinations as well as training for examinee are included in the qualification process of the QDA program. Various damage mechanisms are included in the practical examination such as wear, thinning, loose part damage, primary-side water stress corrosion cracking (PWSCC), and outside-diameter inter granular attack/stress corrosion cracking (OD IGA/SCC). They contain indications of all current degradation mechanisms covering steam generator operating experience. In this paper, we describe the QDA program in detail and the implementation results for the domestic analysts.

\section{Performance Demonstration}

\subsection{QDA Program}

According to the EPRI steam generator examination guidelines, an individual seeking qualification as a QDA should be certified Level II or Level III for the eddy current testing. To be considered eligible for the QDA examinations, applicants should complete the training course which consists of a minimum of 40 hours. The training program includes formal classroom and structured practical laboratory exercises. Design, operating experience and industry pulled-tube experience are included in the lecture material. The QDA proctor trains applicants so that they can obtain the knowledge for the calibration procedures and analysis techniques. To be considered a QDA after the completion of training, an analyst should pass both the written and practical examinations for all damage mechanisms available at the time of testing. The written examination contains a minimum of forty questions covering the lecture material. A grade of at least $80 \%$ are required to pass the written examination.

The practical examination consists of eddy current data sets that are randomly selected and contain indications of all current damage mechanisms covering steam generator operating experience. Each damage mechanism is represented by a data set. The expert opinion is used to establish eddy current truth for grading purposes. Damage mechanism categories included in the practical examination are thinning, support structure wear, OD IGA/SCC, PWSCC, and loose part wear. Adequate numbers of flawed and unflawed grading units are used to meet the probability of detection (POD), statistical confidence level (CL), and false-call requirements as shown in Table 1. The practical examination contains a minimum of 11 flawed grading units for each damage mechanism category where only detection is being applied. The number of unflawed grading units selected for the practical examination is equal to at least twice the number of flawed grading units.

In constructing Table 1, calculations from the binomial distribution determined the

Table 1 Performance demonstration test matrices for flaw detection

\begin{tabular}{c|c|c|c}
\hline $\begin{array}{c}\text { Flaw } \\
\text { Detection } \\
\geq 40 \%\end{array}$ & $\begin{array}{c}\text { Minimum } \\
\text { Acceptance } \\
\text { Criteria for } \\
\text { Detection at } \\
80 \% \text { POD } \\
90 \% \text { CL }\end{array}$ & $\begin{array}{c}\text { Minimum } \\
\text { Number of } \\
\text { Unflawed } \\
\text { Grading } \\
\text { Units }\end{array}$ & $\begin{array}{c}\text { Maximum } \\
\text { Number of } \\
\text { False Calls }\end{array}$ \\
\hline 11 & 11 & 22 & 2 \\
\hline 17 & 17 & 34 & 3 \\
\hline 18 & 17 & 36 & 3 \\
\hline 24 & 23 & 48 & 4 \\
\hline 25 & 23 & 50 & 5 \\
\hline 31 & 29 & 62 & 6 \\
\hline 32 & 29 & 64 & 6 \\
\hline
\end{tabular}


minimum number of successes, $x$ required in examining a flaw data set of size $n$ to ensure, at a CL of $90 \%$, that the actual POD is $80 \%$ or greater. The binomial distribution provides the probability of each possible outcome over a specified number of trials when only two outcomes are possible on each trial-sucess or failure-and the likelihood of a success or failure is known or assumed. The probability of exactly $x$ successes in $n$ trials, when the probability of success on each trial is $p$, is calculated as follows:

$$
P(x \mid n, p)=\frac{n !}{x !(n-x) !} p^{x}(1-p)^{n-x}
$$

This expression can be used to calculate the minimum number of detections required from a sample set of given size to be ensured, at a confidence level of $90 \%$, that the actual POD is equal to or greater than 0.8 . Starting with the largest number of detections possible $(n)$, the probability of that number of detections is calculated and that of each lesser number of detections $(n-1, n-2$, etc.) so that when the probabilities are added together they do not exceed a combined probability of 0.1 .

Table 2 Performance demonstration test matrices for flaw detection and sizing

\begin{tabular}{c|c|c|c|c|c|c}
\hline $\begin{array}{c}\text { Flaw Detection Acceptance Criteria for } \\
\text { a Given Damage Mechanism Category }\end{array}$ & \multicolumn{2}{c}{$\begin{array}{c}\text { False Call } \\
\text { Acceptance Criteria }\end{array}$} \\
\hline $\begin{array}{c}\text { Total No. of } \\
\text { Flawed } \\
\text { Grading } \\
\text { Units }\end{array}$ & $\begin{array}{c}\text { No. of } \\
\text { Flawed } \\
\text { Grading } \\
\text { Units }\end{array}$ & $\begin{array}{c}\text { Min. } \\
\text { Acceptance } \\
\text { Criteria for } \\
\text { Detection }\end{array}$ & $\begin{array}{c}\text { Max. } \\
\text { No. of } \\
\text { Unflawed } \\
\text { Grading } \\
\text { Units }\end{array}$ & $\begin{array}{c}\text { Max. No. } \\
\text { of False } \\
\text { Calls }\end{array}$ \\
\hline \multicolumn{2}{c|c|c|c|c|c|c|c|c|c|c|c|}{} \\
\hline 16 & $40 \%$ & $\begin{array}{c}\geq \\
40\end{array}$ & $40 \%$ & $40 \%$ & & \\
\hline 17 & 5 & 11 & 4 & 11 & 32 & 3 \\
\hline 18 & 6 & 12 & 5 & 12 & 36 & 3 \\
\hline 25 & 8 & 17 & 7 & 17 & 50 & 5 \\
\hline 26 & 8 & 18 & 7 & 17 & 52 & 5 \\
\hline 36 & 12 & 24 & 10 & 23 & 72 & 7 \\
\hline 37 & 12 & 25 & 10 & 23 & 74 & 7 \\
\hline 46 & 15 & 31 & 12 & 29 & 92 & 9 \\
\hline 47 & 15 & 32 & 12 & 29 & 94 & 9 \\
\hline
\end{tabular}

Practical examination contains a minimum of 16 flawed grading units for each damage mechanism category where both detection and sizing are being applied as shown in Table 2 . The number of unflawed grading units selected for the practical examination is equal to at least twice the number of flawed grading units.

Practical examinations for each data set are graded by one or more of the following methods depending on the technique applicability of detection, sizing, and orientation. Personnel are considered qualified for detection of a specific damage mechanism if all of the following requirements are met:

(1) A POD of at least $80 \%$, at a $90 \%$ CL for flawed grading units $\geq 40 \%$ through wall (TW).

(2) Detection of at least $80 \%$ of the flawed grading units $<40 \% \mathrm{TW}$.

(3) The number of reported false calls is no more than $10 \%$ of the total number of unflawed grading units.

Personnel are considered qualified for performing sizing measurements on a specific damage mechanism if a root mean square error (RMSE) of less than or equal to $10 \%$ is demonstrated. The sample set, RMSE, is calculated using the following equation:

$$
R M S E=\sqrt{\frac{1}{n} \sum_{i=1}^{n}\left(M_{i}-T_{i}\right)^{2}}
$$

where, $M_{i}$ is the eddy current measured flaw parameter assigned by the individual analyst for the $i$ th indication, $T_{i}$ is the eddy current measured flaw parameter for the $i$ th indication determined by expert opinion, and $n$ is the number of measured grading units in the data set.

Personnel are considered qualified for determining orientation of a specific damage mechanism if the correct orientation is reported on at least $80 \%$ of the flawed grading units. Only those flaws which are detected are considered in the orientation calculation. 
2.2 Implementation Status of the QDA Program

An individual seeking qualification as a QDA should complete the training course of a minimum 40 hours including formal classroom and structured practical laboratory exercises. When an individual successfully completes the training course, the individual may take the written and practical examination. If an individual fails to pass either the written examination or any applicable technique parameter of the practical examination, then the individual has the option of undergoing a re-examination following the required reviews, training or waiting period as defined in the EPRI Guidelines [4]. The written examination may be conducted an open book format. If an individual fails to pass the written examination, the individual should receive additional training on the related topics or subjects prior to re-examination. If the individual fails to attain a passing score on a written re-examination, a five-day wait is required before a subsequent re-examination may be taken. Each written reexamination contains a minimum of 40 questions and is assembled by a random selection process which may be augmented by the inclusion of questions specific to the areas of deficiency.

If an individual fails to pass any criteria in the practical examination for given damage mechanisms, a practical re-examination is given for each of data sets in which the individual received less than a passing grade. Missed indications should be reviewed and no waiting period is required prior to the initial reexamination. Prior to a second re-examination, the individual should complete additional training as deemed necessary by the proctor. If the individual fails to attain a passing score after the second re-examination, a 30-day waiting period, with 40 hours of additional training, are required. This new examination includes the entire written and practical examination. No credit is given for the previous three practical examinations or for the written examination.

The performance demonstration program for steam generator tubing analysts in Korea was officially started on July 1, 2004. The QDA program of version 3.3 was initially used for the performance demonstration of the domestic analysts. Pitting, thinning, support structure wear, impingement and OD IGA/SCC of bobbin data and PWSCC and ODSCC of rotating probe data were included in the practical examination of this version. However, in 2010, the EPRI released the version 4.02 of the QDA test in which loose part wear of bobbin and rotating probe data and PWSCC of bobbin data are newly included. While the pitting and impingement damages were excluded in this new version because they have not been active damage mechanisms any more.

A total of 99 analysts had taken the QDA test by the end of 2009 using the old version, V3.3, based on the revision 6 of EPRI Guidelines. Since then, fourteen analysts have taken the QDA test using the new version, V4.02. Most applicants passed the written examination for the new version as well as the old one. Therefore, the results only for the practical examination were analyzed in detail in this paper.

As shown in Fig. 1, the pass rate in the practical examination for the V3.3 was $28.3 \%$ in the first examination, $48.5 \%$ in the second and $18.2 \%$ in the last, respectively. The overall pass rate was $94.9 \%$ for the old version. Fig. 2 shows that the result for the new version is stricter than the old version. For the new version, there was no individual who passed in the first examination. The pass rate was $7.1 \%$ in the second examination and $64.3 \%$ in the last, respectively. The overall pass rate was $71.4 \%$ for the version 4.02. The pass rate for the version 4.02 was lower than for the version 3.3 because the newly included damage mechanisms 


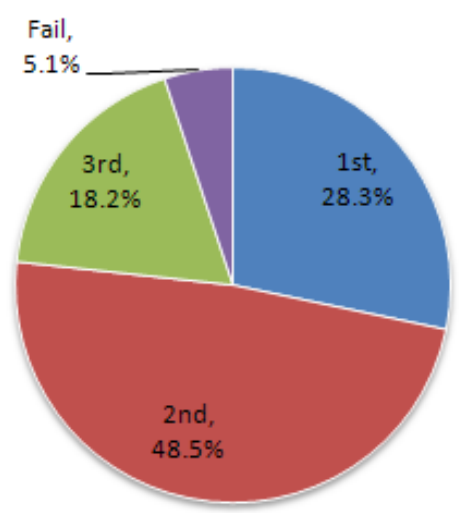

Fig. 1 Pass rate of QDA practical examination for the old version

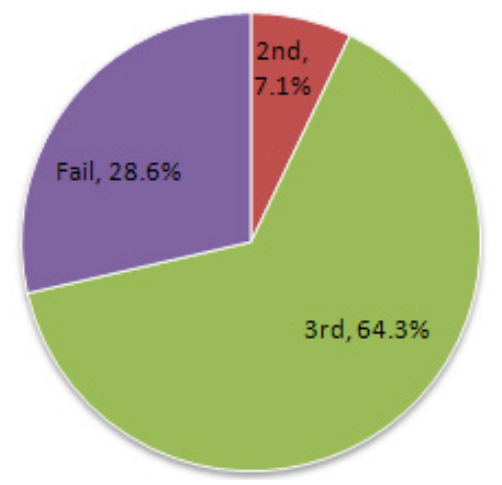

Fig. 2 Pass rate of QDA practical examination for the new version

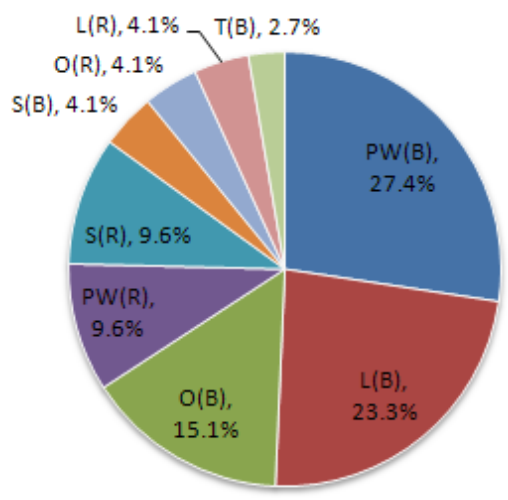

Fig. 3 Failure rate of QDA practical examination for each damage mechanism of the new version

seemed to be unfamiliar to domestic analysts. The failure rate of the QDA test for each damage mechanism using the new version is shown in Fig. 3. In Fig. 3, the $\mathrm{PW}(\mathrm{B})$ is an abbreviation for primary water stress corrosion cracking of bobbin data, L(B) for loose part wear of bobbin data, $\mathrm{O}(\mathrm{B})$ for outside diameter inter granular attack/stress corrosion cracking of bobbin data, $\mathrm{PW}(\mathrm{R})$ for primary water stress corrosion cracking of rotating probe data, $S(R)$ for support structure wear of rotating probe data, S(B) for support structure wear of bobbin data, $\mathrm{O}(\mathrm{R})$ for outside diameter inter granular attack/stress corrosion cracking of rotating probe data, $L(R)$ for loose part wear of rotating probe data and $T(B)$ for thinning of bobbin data. The results show that the primary water stress corrosion cracking and the loose part wear for bobbin data are the dominant degradation mechanisms for which domestic analysts have failed to find flaws.

Recently, signal analysis for steam generator tubing in nuclear power plants, especially for the ODSCC in the tube support plate, is a major issue in Korea. Although an analysis guideline depends on inspection conditions such as tube material, diameter, thickness and frequencies used, the analysis method for ODSCC in the QDA test may be considered as a reference.

The comparison or analysis for the QDA results of foreign countries was not included in this paper because the EPRI has not administered the results for them.

\section{Conclusions}

The new version of the QDA program has been used for the domestic steam generator tubing analysts since 2010 in accordance with the Notice 2012-10 of the Nuclear Safety and Security Commission in Korea and the EPRI steam generator examination guidelines, revision 7. The pitting and impingement damage mechanisms for bobbin data were excluded in the practical examination data set of the new version, while loose part wear for both bobbin 
and rotating probe data and primary water stress corrosion cracking for bobbin data were newly included. The pass rate of the QDA practical examination using the old version was about $95 \%$, whereas it was about $71 \%$ using the new version. The primary water stress corrosion cracking and loose part wear for bobbin data were the dominant degradation mechanism for which domestic analysts have failed to find flaws in the new version. The reason seems to be because the analysts are unfamiliar with the newly included damage mechanisms. It is expected that the QDA program contributes to improve the performance of domestic analysts.

\section{Acknowledgement}

This work was accomplished by the Performance Demonstration Program supported by the Korea Hydro \& Nuclear Power Co., Ltd.

\section{References}

[1] American Society for Nondestructive Testing, Inc., "Personnel Qualification and Certification in Nondestructive Testing," Recommended Practice No. SNT-TC-1A, Columbus, Ohio, USA (1984)

[2] American Society for Nondestructive Testing, Inc., "ASNT Standard for Qualification and Certification of Non- destructive Testing Personnel," ANSI/ASNT CP-189, Columbus, Ohio, USA (1989)

[3] Nuclear Safety and Security Commission, "Regulation on In-service Inspection of Nuclear Facilities," NSSC Notice 2012-10, Korea (2012)

[4] Electric Power Research Institute, "Pressurized Water Reactor Steam Generator Examination Guidelines: Revision 7," EPRI SGMP TR-1013706, Palo Alto, California, USA, pp. G1-G14 (2007) 